\title{
Next-generation tools to control biting midge populations and reduce pathogen transmission
}

\author{
Phillip Shults ${ }^{1 *} \mathbb{D}$, Lee W. Cohnstaedt ${ }^{3}$, Zach N. Adelman ${ }^{1}$ and Corey Brelsfoard ${ }^{2}$
}

\begin{abstract}
Biting midges of the genus Culicoides transmit disease-causing agents resulting in a significant economic impact on livestock industries in many parts of the world. Localized control efforts, such as removal of larval habitat or pesticide application, can be logistically difficult, expensive and ineffective if not instituted and maintained properly. With these limitations, a population-level approach to the management of Culicoides midges should be investigated as a means to replace or supplement existing control strategies. Next-generation control methods such as Wolbachia- and genetic-based population suppression and replacement are being investigated in several vector species. Here we assess the feasibility and applicability of these approaches for use against biting midges. We also discuss the technical and logistical hurdles needing to be addressed for each method to be successful, as well as emphasize the importance of addressing community engagement and involving stakeholders in the investigation and development of these approaches.
\end{abstract}

Keywords: Culicoides sonorensis, Wolbachia, IIT, SIT, Population suppression, Population replacement, Pathogen transmission

\section{Background}

Biting midges in the genus Culicoides are small hematophagous insects that feed on a variety of vertebrate hosts. Culicoides midges are responsible for transmitting over 110 viral, protozoan and filarial pathogens worldwide $[1,2]$. The diseases caused by these pathogens are of veterinary, medical and ecological importance, and include bluetongue (BT), epizootic hemorrhagic disease (EHD), African horse sickness virus (AHSV), Schmallenberg disease, and Oropouche fever [3, 4]. Multiple outbreaks of bluetongue virus (BTV) of different serotypes, topotypes (regional variants of particular serotypes) and strains have been recorded in Europe in recent decades $[5,6]$. One of the largest European outbreaks to date

\footnotetext{
*Correspondence: ptshults@tamu.edu

1 Texas A\&M University, 370 Olsen Blvd, College Station, TX 77843, USA

Full list of author information is available at the end of the article
}

resulted in economic damage greater than US\$150 million (USD) in the Netherlands alone [7]. While severe disease outbreaks can cause a substantial loss in livestock numbers, their main economic impact stems from international trade restrictions and bans [8]. Worldwide estimates of direct and indirect losses due to just BT have been estimated to top USD 3 billion annually [9].

Methods of treatment and prevention for Culicoidestransmitted pathogens are broad and untargeted, or reactive to an outbreak, resulting in insufficient population reduction to prevent transmission [10, 11]. Current management practices for biting midges use a combination of broad-spectrum pesticide applications, larval habitat source reduction and behavioral management of livestock [12, 13]. Implementing these strategies over a large area can be difficult, expensive and/or harmful to the environment. The availability of vaccines is also limited for many diseases caused by Culicoides-transmitted

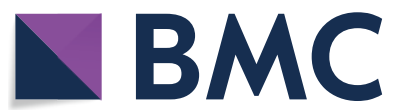

(c) The Author(s) 2021. This article is licensed under a Creative Commons Attribution 4.0 International License, which permits use, sharing, adaptation, distribution and reproduction in any medium or format, as long as you give appropriate credit to the original author(s) and the source, provide a link to the Creative Commons licence, and indicate if changes were made. The images or other third party material in this article are included in the article's Creative Commons licence, unless indicated otherwise in a credit line to the material. If material is not included in the article's Creative Commons licence and your intended use is not permitted by statutory regulation or exceeds the permitted use, you will need to obtain permission directly from the copyright holder. To view a copy of this licence, visit http://creativeco mmons.org/licenses/by/4.0/. The Creative Commons Public Domain Dedication waiver (http://creativecommons.org/publicdomain/ zero/1.0/) applies to the data made available in this article, unless otherwise stated in a credit line to the data. 
pathogens. Attenuated vaccines are available for BTV, although their effectiveness varies as they often only protect against a single serotype $[3,12]$. Inactivated viral vaccines for BTV have also been shown to be effective, but would be expensive for large-scale livestock applications in enzootic areas $[14,15]$. With the concerns and limitations of the current control methods, research efforts are sorely needed to develop environmentally friendly and sustainable methods for Culicoides midge control.

The use of autocidal and next-generation control methods is an attractive option for implementation in Culicoides systems to reduce or replace natural populations and prevent disease transmission. These population-level control techniques utilize the biology of the target species to reduce the total number of vectors in a population $[16,17]$. Suppression methods inhibit a target organism's ability to produce viable offspring through the release of sterile or incompatible males. This reduction in potential vectors is presumed to lead to a reduction in pathogen transmission. Conversely, methods used for population replacement aim to lower virus transmission by reducing the vector competency of individuals within the population. Replacement strategies have garnered significant attention for the control of dengue virus (DENV) transmission in the Aedes aegypti mosquito [18-21]. Individuals resistant to pathogen transmission can be released into the environment until the disease refractory phenotype reaches fixation, thus replacing the wild population with one that has a limited ability to transmit pathogens.

Culicoides sonorensis, an important vector of BT and EHD viruses in North America, is a well-studied species with a significant number of molecular resources available, making it a prime candidate for the investigation of next-generation control methods [22]. Culicoides sonorensis has been reliably maintained in colonies for over 60 years, and existing rearing protocols can be scaled for mass production and releases [23, 24]. The genome of $C$. sonorensis has been published along with several reference transcriptomic studies [25-28], and further annotation and chromosomal mapping/assembly will help to maximize the utility of these resources. There are also several cell lines of $C$. sonorensis which will aid in the screening process for effector genes or Wolbachia strains that might interfere with pathogen replication prior to in vivo experiments [22]. Here we report our assessment of the potential application of autocidal, genetically and Wolbachia-based control techniques to reduce biting midge populations and as methods to limit pathogen transmission using C. sonorensis as a model. The outcome of initial tests within this more tractable species will help inform whether significant resources should be allocated to developing similar control methods in other Culicoides vector species.

\section{Management tools}

\section{Sterile insect technique}

The sterile insect technique (SIT) is an autocidal, or "self-killing", approach to pest control based on the mass inundative releases of irradiated sterile males. When irradiated males mate with wild females, the lack of viable sperm transferred ultimately causes the reduction of natural populations, provided the releases are sustained [29, 30] (Fig. 1a). SIT approaches have been used successfully to control Cochliomyia hominivorax (primary screwworm), Glossina austeni (tsetse fly) and Ceratitis capitata (medfly) [31-33], and are an attractive option for vector control as these released males do not negatively impact the host via blood-feeding or by transmitting pathogens. Additionally, this approach is environmentally friendly as it is species-specific and self-limiting [34]. As an initial step towards the development of an SIT approach targeting biting midges, Jones [23] exposed males and females from the USDA "AA" colony line of $C$. sonorensis to varying amounts of gamma radiation. Sterility of $95-100 \%$ was observed in males exposed to 10,000-15,000 rad, and this infertility lasted for up to five subsequent matings. It should be noted that Jones lists his measure of radiation dosage as " $R$ " which could be either rads or roentgens. Females exposed to these doses showed a drastic decrease in the number of eggs laid. Jones [23] also demonstrated sterilization of pupae, although in many cases a higher dose $(20,000-30,000 \mathrm{rad})$ was needed to prevent males from recovering fertility. A potential advantage to irradiating pupae is that fewer adverse side effects might be associated with transporting pupae as compared to the more fragile adult stages, similar to reports from shipping adult mosquitoes [35]. Even though C. sonorensis were exposed to relatively high amounts of radiation, little to no somatic damage was observed [23, 24]. Further studies are needed to fully investigate the use of SIT to control Culicoides midges; however, its simplicity and success in controlling other Dipterans makes this an promising approach.

\section{Wolbachia-based strategies}

Wolbachia is an obligate intercellular bacterium found in a multitude of insect orders that is estimated to infect up to 55\% of insect species [36]. Wolbachia has been demonstrated to cause reproductive phenotypes in its infected hosts, including male-killing, feminization of genetic males, parthenogenesis and cytoplasmic incompatibility (CI) [36]. The most well-studied reproductive modification is $\mathrm{CI}$ because of its applicability for insect vector control. CI results when a male 
infected with Wolbachia mates with an uninfected female or a female with a different Wolbachia infection type. The result of $\mathrm{CI}$ is that females in incompatible crosses produce non-viable offspring (i.e. eggs that do not hatch). Low-density Wolbachia infections naturally occur in wild populations of several species of Culicoides midges in Europe, Australia and the USA [3739]. Wolbachia infections have also been demonstrated in several mosquito species to induce disease refractory phenotypes [40-44]. If Wolbachia strains that induce CI or pathogen refraction in their Culicoides hosts can be identified and transfected into important vectors, Wolbachia-based strategies may be a viable approach for use against Culicoides midges.

\section{Wolbachia-based IIT}

Wolbachia-based IIT approaches are based upon mass releases of incompatible Wolbachia-infected males, which can lead to suppression and potential elimination of a localized vector population (Fig. 1b) [45]. Similar to SIT, IIT also shares the same limitations of relying on consistent mass rearing and release of only males, although there is no need for specialized irradiators or radioactive materials for sterilization since Wolbachia induces CI. Fluorescent in situ hybridization experiments have shown localization of Wolbachia infections in the midgut, testes and ovaries of $C$. sonorensis [39]. The localization of Wolbachia infections in the reproductive tracts of $C$. sonorensis is suggestive that Wolbachia may be influencing the reproductive system of its Culicoides host [46]. Furthermore, infections identified in C. sonorensis are in similar Wolbachia clades that result in CI in other insects [46]; however, Wolbachia-induced CI or other reproductive phenotypes remain undocumented in any Culicoides spp. Additional studies are needed to examine for Wolbachia-induced CI among Culicoides species harboring natural Wolbachia infections. Field and laboratory trials have shown promising results by reducing mosquito populations in several species [47, 48]. Resulting technology and lessons learned from these studies can be used to help adapt IIT for use against Culicoides midges.

\section{Wolbachia-based population replacement}

Particular Wolbachia variants (e.g. the wMel strain) partially block DENV, chikungunya virus, Zika virus and yellow fever virus transmission without impacting Aedes aegypti fitness [40-44]. As Wolbachia-infected females can mate and produce viable offspring with infected and uninfected males alike, their resultant reproductive advantage can drive a given disease refractory phenotype into a natural population (Fig. 1d). Releases of Wolbachia-infected mosquitoes by the World Mosquito Programs are ongoing in 15 countries, with a focus on reducing DENV transmission (www.eliminate.dengu e.com). These releases have been remarkably successful at replacing natural populations with Wolbachia-infected individuals and are showing reductions in DENV transmission [49]. It is presumed that these Wolbachia infections are directly competing with the pathogens for intracellular resources or the infection is resulting in an upregulation of the host's immune system. Either or both of these could, in turn, influence the pathogen in the insect host $[45,50]$. Recent transfection of $C$. sonorensis cell lines with a novel Wolbachia type suggest an upregulation of the host immune system, which may be associated with a pathogen-blocking phenotype; however, this needs to be tested in vivo [51]. Population replacement approaches are an attractive option for Culicoides disease control as they do not require the continued release of individuals after the desired phenotype reaches fixation in a population, although this self-sustainment also increases ecological concerns. After the establishment of Wolbachia, restoring the natural population or eliminating the introduced population may be difficult in the event of any undesirable outcomes [52].

\section{Transgene-based strategies}

Whereas SIT elicits sterility via chromosomal damage to the reproductive cells, and certain Wolbachia species cause CI, infertility can also be induced molecularly through genetic modifications. Manipulating an insect's genome through the insertion of genes or altering the expression levels of existing genes can produce individuals with a desired genotype [53, 54]. Local vector populations can be suppressed or pathogen transmission can be blocked by releasing genetically modified (GM) individuals carrying a lethal or pathogen-resistant transgene (reviewed in [55]). Autocidal or Wolbachiabased approaches rely on the disruption of fertilization or early embryonic development, whereas transgene-based approaches allow more control over the timing of gene

(See figure on next page.)

Fig. 1. Proposed suppression and replacement approaches for Culicoides population and disease control. a Sterile insect technique (SIT) approach, b Wolbachia-based incompatibly insect technique (IIT) approach, c male-dominant lethal population suppression and $\mathbf{d}$ Wolbachia-based population replacement and genetic modification gene drive approaches. In all figures, the light-blue Culicoides midge symbols represent wild-type (WT) individuals 

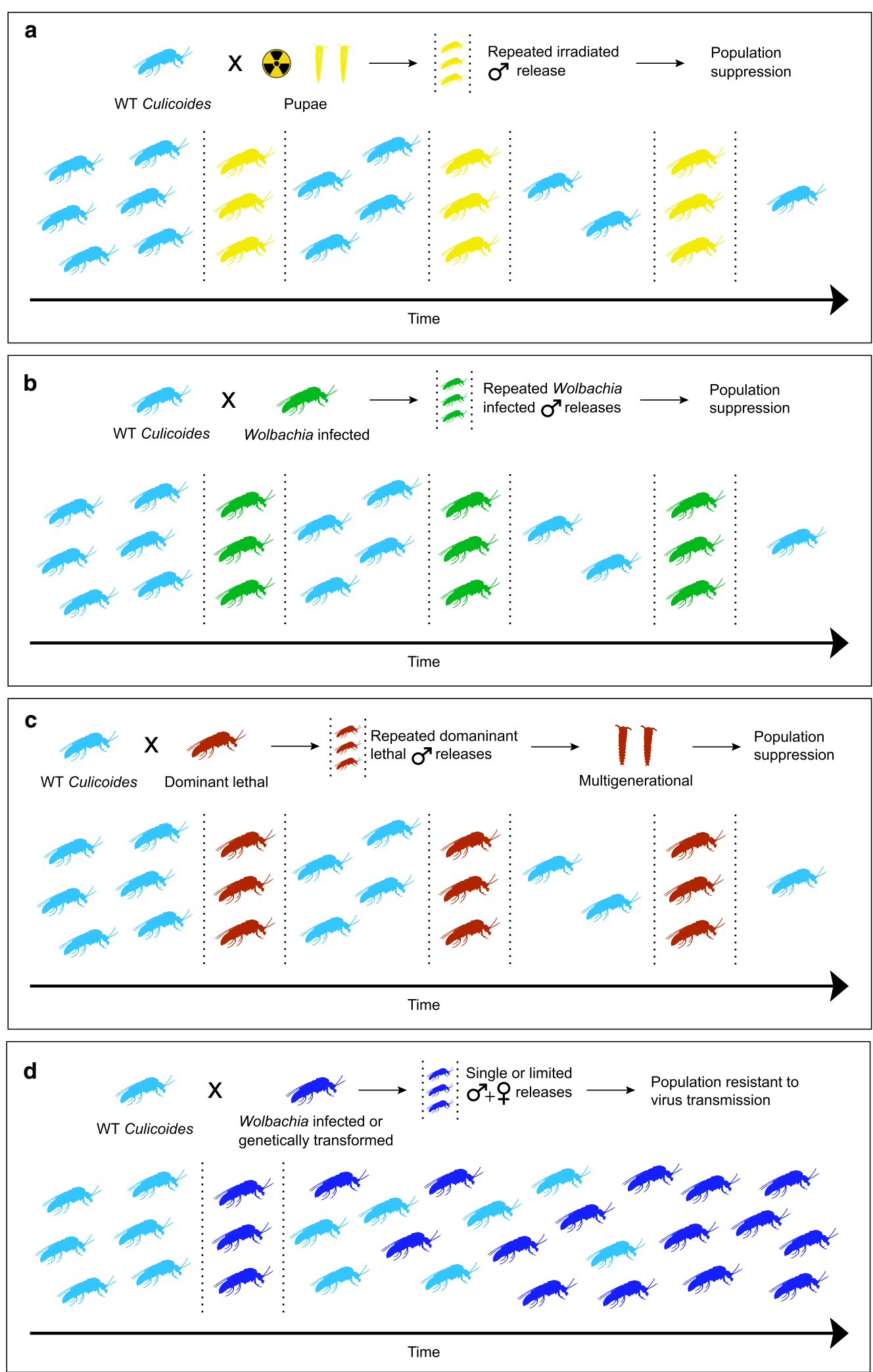
expression and any associated consequences. For example, a lethal transgene can be designed to activate only during the pupal stage. This means the released GM individuals can develop normally as a larva and actively compete with wild types for resources, potentially increasing the power of the approach. Genetic engineering can also be used in conjunction with conventional SIT or IIT [56, 57], although the designation of the organisms as GM will affect when and where this strategy can be used. Transgene-based control methods will face some of the same logistical challenges associated with mass rearing and release, but they will also face public resistance due to the designation of these insects as genetically-modified organisms (GMO). In fact, the use of GMOs are banned outright in some countries, a situation unlikely to change in the foreseeable future.

Currently, methods for the genetic modification of Culicoides midges have not yet been described; however, tools such as CRISPR (clustered regularly interspaced short palindromic repeats)-Cas9 [58] and the broadly active transposable element piggyBac [59] are likely to be effective in biting midges, given their success in many other Diptera. Once validated methods are in place, genetic modifications proposed as a means to control other vector populations, such as mosquitoes, can be used as a template to create similar strains of transgenic Culicoides midges [60,61]. Additionally, without a phylogeny for the genus, it will be hard to predict what information will be transferable between or with subgenera. As gene families can evolve independently between divergent groups, the genes associated with pathogen transmission or midge reproduction/development may be highly variable within the genus. Separate transgenic suppression or replacement methods may need to be developed for specific midge species, further complicating this approach.

\section{Self-limiting transgene-based population suppression}

Genetic control techniques such as RIDL (Release of Insects carrying a Dominant Lethal) can be adapted for use in Culicoides [55] (Fig. 1c). Males carrying a dominant lethal transgene are mass-released into a population with all of their progeny inheriting a copy of this transgene. The female offspring will subsequently die; however, the male offspring will survive and pass this transgene to $50 \%$ of their progeny offering multigenerational control. To maintain transgenic lines within the production facility, this approach requires the development of an inducible sex-lethal system to turn off expression of the lethal gene, similar to the Tet-on/off [62]. These lines can also be integrated into an SIT or IIT approach as a means of improving the speed and accuracy of sex-separation.
Transgene-based population replacement and gene drive Certain Wolbachia spp. are capable of overcoming normal Mendelian inheritance, with the result that these strains can increase in frequency in the host population without actually offering a benefit or selective advantage. Similar methods of increasing transgene frequency in wild populations have been proposed to spread engineered transgenes to be used in population replacement approaches; these are termed gene drive (reviewed in [63]). A wide array of gene drive architectures have been developed in other Diptera, such as Drosophila [19, 64, 65] and mosquitoes [66-69]. These architectures will be helpful for the development of any future Culicoides midge population replacement strategy as the general principles of pathogen resistance and gene drive will be the same [50, 70, 71] (Fig. 1d). The effects of natural Wolbachia infections in target Culicoides species on a gene drive approach could also be nullified by the development aposymbiotic strains via antibiotic treatments. Any population replacement strategies developed using a gene drive system can be expected to vary in terms of persistence and invasiveness in the environment, and thus proper risk assessment and community engagement will be vital before any field-based evaluation or implementation [45, 72].

\section{Research gaps concerning the use of novel control approaches against Culicoides Investigation of sterility, $\mathrm{Cl}$, genetic modification and pathogen-blocking phenotypes}

The next-generation management techniques mentioned above rely on the creation of a targeted phenotype that is subsequently released into natural populations. The mechanisms underlying these approaches all vary; however, each will follow similar steps during development (Fig. 2). Solutions for overcoming hurdles in one strategy will likely translate to the others. Mating assays are often used to test the efficacy of a created phenotype, measuring clutch size, hatch rate, immature survival and inheritance $[45,67]$. Such assays can only be performed if the target species mates under laboratory conditions, and many Culicoides spp. form mating swarms at established landmarks (environmental structures, larval habitats, the host, etc.) [73]. As colonies of C. sonorensis exist, laboratory mating assays should not impede the development of next-generation control strategies against this species.

Further work is needed to refine the radiation sterilization of C. sonorensis using modern methods and equipment, but such work can be started immediately. To introduce a Wolbachia strain or perform genetic modifications, a protocol for the microinjection of biting midge eggs must be established. While there are well-established protocols for microinjecting mosquito eggs [74] 
and Drosophila and sandfly eggs [75], Culicoides eggs are more elongated and have less volume, and are thus anticipated to be more difficult to manipulate (Fig. 3). Until successful microinjections can be conducted, this will be a barrier to the implementation all Wolbachia- and genetically-based strategy.

In developing new protocols for genetically-modified biting midges, we anticipate that the initial modifications would be the insertion of a marker gene, such as green fluorescent protein (for transposon-based approaches), or easily scorable visible markers, such as white-eyes (for CRISPR/Cas9 based approaches) [76, 77]. Following the validation of injection methods and transposable element (TE) integrations, the TE-based random insertion of candidate transgenes will help determine optimal integration site [78]. Such sites could be re-used using targeted recombinases [79] or CRISPR-Cas9 [80]. Research suggests that BTV vector competence is associated with the expression of glutathione $S$ transferase (GST) and the antiviral helicase (SKi2) [28, 81]; thus, altering the expression of the two genes encoding these proteins with inserted promotors or suppressors may be a first step towards a genetically-based control strategy.

Many different cell lines derived from $C$. sonorensis exist, and their susceptibility to a number of BTV and epizootic hemorrhagic disease virus (EHDV) serotypes are known [22]. Additionally, cell lines derived from $C$. nubeculosus have recently been established [82]. As an initial step to investigate virus inhibitory effects induced by Wolbachia infections or transgene-based genetic modifications, the rate of viral proliferation in modified cells can be compared to that reported in previous studies. If inhibition is found, running these assays on lines from both species will aid in understanding the mechanisms behind this inhibition.

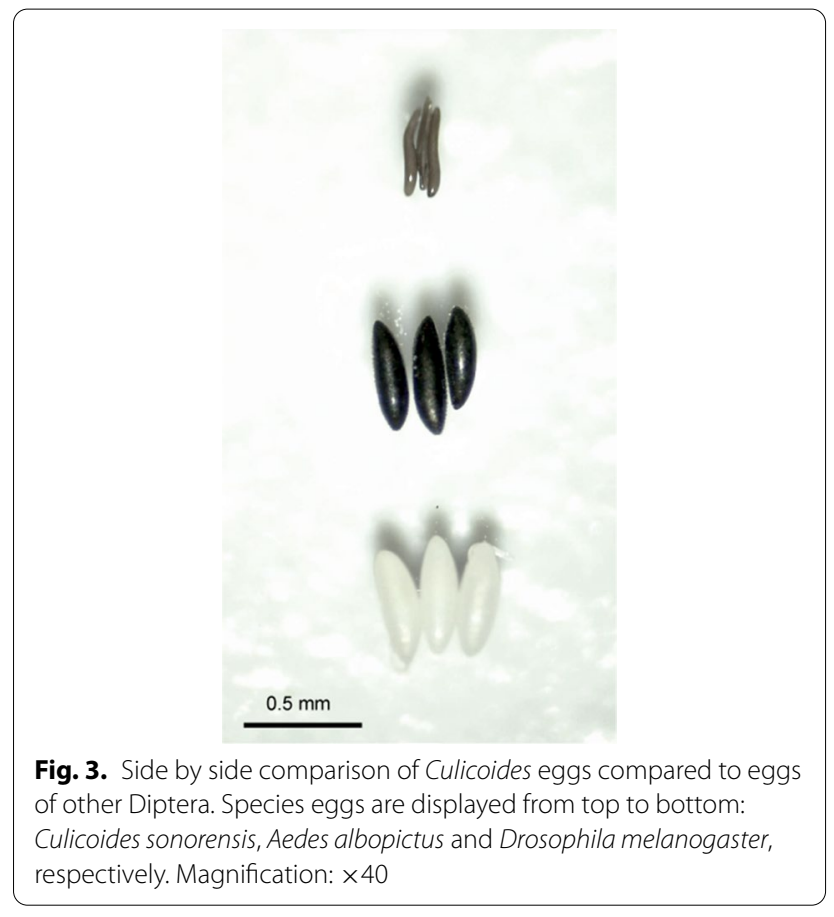

\section{Establishment of laboratory colonies and the logistics of mass release}

For SIT, IIT or GM suppression methods to be effective, the target biting midge species must be continuously mass-reared on the scale of tens of thousands of individuals. Whereas replacement strategies do not require inundative releases, they still require the repeated release of substantial numbers of individuals proportional to the natural population. Culicoides sonorensis is one of two species of Culicoides currently maintained in colonies. Initial colonization of wild-collected $C$. sonorensis can be

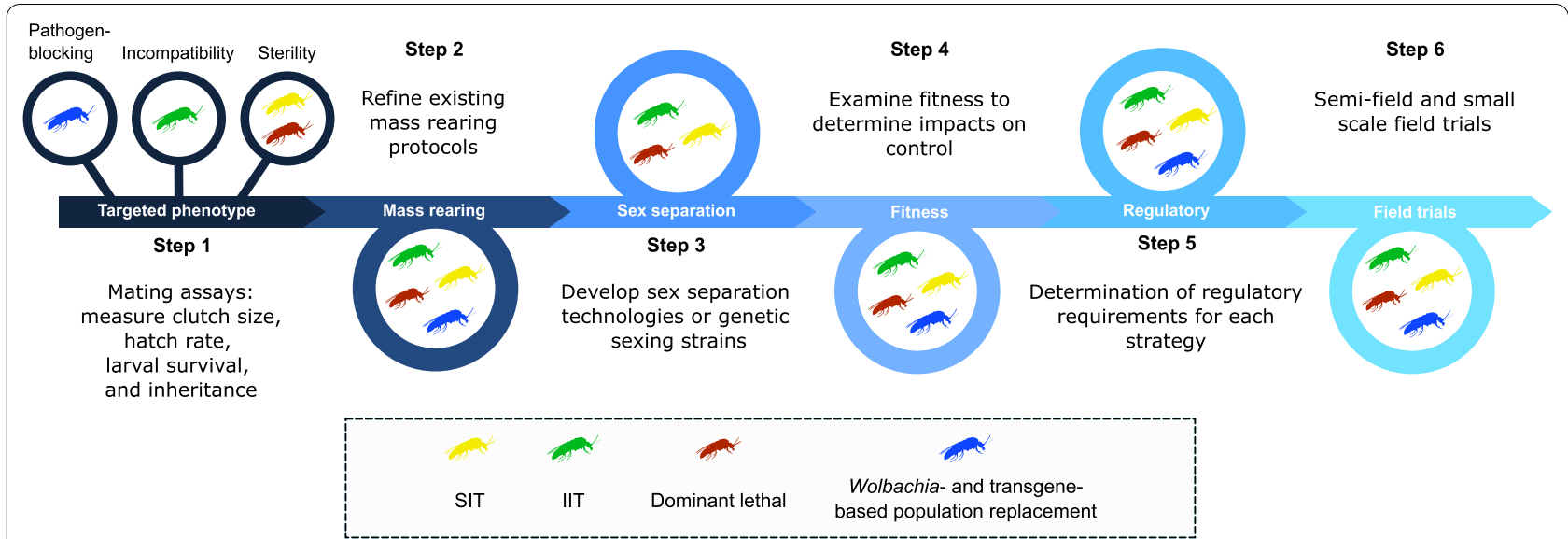

Fig. 2. Systematic steps for future research to address hurdles for the development of IIT, population replacement, genetically-based and/or SIT approaches 
difficult as well, but there are procedures and protocols in place to aid any attempts $[23,24]$. The number of individuals currently being produced ( 2 million per year) is only constrained by space and labor and can be scaled upward as needed. The colonization of other Culicoides species has been attempted, but to date these efforts have been met with limited success or the discontinuation of colonies $[22,83]$. The inability to successfully colonize and maintain a species in the laboratory would render these control methods ineffective for that species, making this an urgent area of research need.

For example, the subgenus Avaritia contains several primary vector species of pathogens associated with livestock disease on four continents [2]. Two of the most significant vectors in Europe are Culicoides imicola and $C$. obsoletus, which transmit BT and Schmallenberg viruses [3]. Culicoides imicola is also a significant vector in Africa where it transmits AHSV. Members of this subgenus feed primarily on a variety large mammals and have the ability to breed in dung, thereby tightly linking their life history with susceptible hosts [84]. Attempts to produce viable offspring from field-collected C. imicola and C. obsoletus have resulted in high oviposition numbers and hatch rates, but high larval mortality [85-87]. Optimization of larval rearing conditions could increase the overall adult yields. Interestingly, results from these studies show an apparent male sex bias from laboratory-reared individuals. The mechanisms behind this bias are unknown, but it may present an additional hurdle in the colonization of these species. Potentially, successful control of one Culicoides species using next-generation management tools will signify that substantial resources should be invested in developing and maintaining colonies of these, or other currently intractable midge species of substantial veterinary importance.

\section{Sex separation technologies}

Sex separation can be a bottleneck in the workflow of mass-rearing insects for inundative release, and for certain approaches, it is vital for continued efficacy [30]. In autocidal and genetically-based suppression methods, the unintended release of females will not affect the overall efficacy of the control strategy. With IIT, however, release of Wolbachia-infected females could spread the infection into the natural population, nullifying any CI from that strain. There are clear sex differences in $C$. sonorensis that are apparent in the adult and pupal stage $[88,89]$, although separating the sexes manually is laborintensive. Sex separation in mosquitoes can be done manually, mechanically, genetically, with insecticideladen blood meals, or with machine vision technologies [90-93]. Many of these techniques could be modified for use in Culicoides midges and evaluated for efficacy and accuracy. Additionally, removal of the females at the adult or pupal stage wastes resources that could be better spent increasing male production. Currently, genetic engineering is the only method that could be used to remove female mosquitoes as larvae. This can be done using a Y-linked fluorescent or visible marker [94, 95], or with conditional sex-lethal genes [62, 96-98]. The remaining males can then be conventionally sterilized, released carrying a transgene or released infected with Wolbachia.

\section{Examination of life-history traits and fitness}

Life-history traits also need to be considered and investigated for autocidal, genetically- and Wolbachia-based approaches. For example, the number of times females will mate can impact the efficacy of certain methods. Infertility caused by mating with sterile males can be undone by a single mating with a wild-type male. Additionally, traits such as longevity, survivorship, fertility and fecundity can be affected by laboratory-reared insects $[93,99,100]$. The release of males that are less fit and less competitive will subsequently reduce the success of these approaches. Female fitness influences the rate at which a Wolbachia strain or transgene will spread in natural populations as part of a replacement approach. Future work needs to include investigating the fitness of individuals from all of the aforementioned strategies in laboratory and field conditions.

\section{Vector-host-pathogen interactions}

The majority of the economically important Culicoidestransmitted viruses can be transmitted by multiple species, and there are likely more vector species yet to be identified [1]. Disease-causing pathogens have been isolated from a number of Culicoides spp., although dissemination and oral transmission need to be demonstrated in many of these cases [2]. Disentangling incidental infections from the species most important for maintaining transmission should be a priority. Doing so will help assess the practicality of using next-generation control techniques against biting midges and identify where they are most likely to succeed. As multiple vector species can occur sympatrically, the management of a single species may not be sufficient to eliminate or possibly even reduce pathogen transmission. The predominant vector species can also change by region; therefore, these species-specific control measures will be limited in their use geographically. However, even regionally managing virus transmission can reduce the risk of incursions into disease-free areas. Finally, in the event of an exotic virus introduction, such as African horse sickness, having additional tools to use in tandem with pesticides and quarantines will be important. 


\section{Regulatory approval}

The use of SIT for the control of insects is bound by few regulatory hurdles in the USA and internationally. Currently, there are no international agreements or regulations on the commercial production and release of sterile insects. That being said, the irradiation procedure is becoming more difficult, with reported delays and denial of shipments of cobalt-60, the common material used for small-scale irradiators. Irradiation using isotopes is subject to federal approval in the USA and by the International Atomic Energy Agency. The use of X-ray radiation to sterilize insects for pest management approaches can address some of the programmatic issues of irradiation procedures. Small-scale X-ray irradiators require less shielding and precautionary measures, are easy to use, are portable and only require an electrical power source [101]. Wolbachia approaches are currently regulated in the USA by the Environmental Protection Agency (EPA). Only one IIT approach, for the mosquito Aedes albopictus, has been approved to date for commercial sales in the USA [47]. Other IIT and Wolbachia-based replacement approaches have been approved for use in multiple countries $[49,102,103]$. Large-scale releases of GM mosquitoes have been carried out in Brazil, Panama and the Cayman Islands [104-106], and the U.S. EPA has issued an experimental use permit for releases in Florida and Texas [107]. Regulatory approval for using Wolbachiaand genetically-based approaches are at the purview of each country performing the releases and could require additional approval from a local governing entity.

\section{Semi-field and small-scale field trials}

Information on the short-range dispersal of Culicoides midges will be useful in determining localized effectiveness of these strategies. Both the males and females of several Culicoides species can disperse 1-3 km, both upwind and downwind, in only a few nights $[108,109]$. Male swarms will form near the larval habitat or at a swarm-marker [110, 111]; however, in the case with $C$. sonorensis, mating occurs on or near the host [73]. As the males of this latter species will move to the host, one centralized release point is likely enough to cover a large area for population suppression. In regards to long-range dispersal, Culicoides midges possess the ability to disperse via jet streams and thus have the potential to establish long distances from a release site $[112,113]$. This behavior will need to be considered during risk assessment of population replacement strategies. Small cage and semi-field trials will also need to be performed for the suggested control approaches, and the work done with mosquitoes can be used as a template in studying Culicoides midges. These trials will determine the efficacy of each approach and act as proof of concept by providing an understanding of fitness effects, mating competitiveness, survival and rates of sterility and/or replacement.

\section{Implementation}

While many species of Culicoides are associated with disease transmission, here we will highlight two systems for which autocidal and next-generation approaches could be applied, namely population suppression of Culicoides belkini and population replacement of C. sonorensis. Some species of biting midge species, such as Culicoides furens in the Caribbean and C. belkini in the South Pacific, are not disease vectors but do adversely impact outdoor activities and tourism, resulting in severe economic impact to the island economies [114-116]. Culicoides belkini populations are excellent targets for population suppression because the isolated island distribution likely limits migration between islands. The Louis Malarde Institute recently completed a $600-\mathrm{m}^{2}$ rearing facility to raise Wolbachia-infected Aedes polynesiensis mosquitoes for population suppression on the Society Islands. This same facility can be used to first colonize and then mass rear the native C. belkini (personal communication with the Laboratory Director Herve Bossin). Local populations or small islands can be targeted to prove efficacy of the population suppression or elimination, which will have significant local support by the community and tourist industry. Culicoides belkini is the only species of biting midge on certain islands, therefore monitoring the population reduction and detecting re-introductions can be coupled with the local Ae. aegypti and Ae. polynesiensis monitoring program with relative ease.

Eliminating or reducing a Culicoides midge population below a theoretical transmission threshold may not be feasible on a continental scale compared to isolated islands. The alternative is a population replacement strategy to reduce a species vectoral capacity. For BTV, EHDV and vesicular stomatitis virus (VSV) in the USA, the best known vector is $C$. sonorensis. The native range of this species is the central and western USA, primarily west of the Mississippi River [10]. Releasing Wolbachiainfected or transgenic $C$. sonorensis with reduced vector competence will not eliminate the population but could help reduce overall virus transmission, even in the presence of other competent vector species [117]. While transmission may not be completely abrogated due to the presence of these other species, pre- and post-release serosurveys of sentinel animals can be used to document any reduction in pathogen transmission $[118,119]$. This in turn can shed new light on the importance of $C$. sonorensis in driving the transmission of BTV and EHDV and help identify other vectors that might be important in this process. Moreover, the range of C. sonorensis is most of the USA west of the Mississippi River; therefore, 
releasing fewer individuals (compared to inundative releases) is desirable due to the probable high effective population size, as has been shown in C. imicola, C. obsoletus and C. brevitarsis [120-122]. Although the ultimate goal is to eliminate viral transmission, the initial goal of next-generation management practices is to prove their effectiveness against biting midges. Again, success or failure with any approach like this can help inform whether similar approaches will be of value for other Culicoides spp.

\section{Engagement and risk assessment Stakeholders}

While hemorrhagic disease (HD) caused by BTV and EHDV is usually subclinical or asymptomatic in goats and cattle, it can cause severe symptoms and subsequent death in deer and sheep [123, 124]. These diseases cost the USA roughly USD 125 million annually [125], and this amount likely underrepresents the current economic loss as seen in more recent estimates of the global impact of BT [126]. Commercial deer breeding is the most heavily impacted livestock industry in North America, and in Europe, sheep are most the most susceptible animals [127-129]. Thus, in regards to biting midge control efforts, these farmers are likely to be a primary stakeholder for the use of novel control approaches, especially during disease outbreaks. The organization and structure within these industries will prove beneficial to community engagement efforts to promote novel control approaches at annual meetings and though farmer associations. Secondarily, the cattle and dairy industries have a financial interest in reducing the transmission of these viruses. Although these animals are asymptomatic, trade restrictions and reduced production are still associated with HD [126]. Farms and ranches are often on large plots of privately-owned land, away from cities and towns. The release of sterile or modified males on these farms can offer localized management while maintaining a comfortable distance from the general public. Community-wide surveys and collaboration with local governments in these areas will determine if the isolation of these releases increases their overall acceptance.

\section{Risk assessment}

Autocidal, genetically-, and Wolbachia-based methods for vector control can be self-limiting or self-sustaining and the risks associated with each should be weighed alongside any potential benefits prior to release [34, 52, 72]. Proper ecological risk assessments of most species of Culicoides midges will be challenging, as certain biological traits remain unknown. For example, of the roughly 1350 species worldwide, the immature stages have been described for $<20 \%$ of the species [112]. For the species that have been described, there are limited diagnostic characteristics available, and identification can be difficult or inaccurate. Surveying larval habitats is less important for SIT or IIT, but some genetically engineered control strategies employ this step in risk assessment and monitoring.

For control methods that rely on sterility or incompatibility, heterospecific mating will not affect the outcome of the program; however, for methods that rely on a drive mechanism, gene flow between closely related species can have unintended consequences. There are a number of species complexes within the genus that hinder proper identification and, depending on the relatedness of the species within the complex, could lead to unintended consequences upon release of modified individuals [84]. Culicoides sonorensis belongs to a complex of three species, which was historically considered to be five subspecies [89]. If $C$. sonorensis is actively hybridizing with closely related species, the risk of introgression increases substantially. Under laboratory conditions, C. sonorensis is able to hybridize with $C$. occidentalis and produce viable offspring for six generations [130]. In nature, prezygotic isolation barriers can still exist to keep these species from mating; however, this study [130] shows the potential for gene flow due to the lack of post-zygotic isolation barriers. No natural hybrids have been confirmed, although analyses using more sensitive markers should be conducted $[131,132]$. As monitoring programs will be in place to ensure the efficacy of a management program, these can also be used to detect unintended outcomes from releasing modified individuals into the environment.

\section{Conclusions}

As novel strains of Culicoides-transmitted viruses continue to spread to new areas [133-135], establishing one or multiple next-generation control methods could provide an effective way to reduce disease transmission. Successful control in one species would provide an outline to adapt these techniques for use in other biting midge pathosystems. Conventional SIT can be the most turnkey option for controlling biting midges, although more work is needed to optimize the radiation dose to minimize any fitness effects attributed to irradiation. Evidence for $\mathrm{CI}$ induced by Wolbachia infections in Culicoides is still needed, but both IIT and Wolbachia-based replacement approaches appear promising. No genetic modification of any Culicoides midge has been reported; therefore, its use in vector control is likely years away, although developing conditional sex-lethal transgenic lines could be useful for integration of an SIT or IIT approach. Any potential Wolbachia- or genetically-induced viral inhibitory effects will need to be demonstrated using in vitro and in vivo 
systems. While this review focused mainly on North America and C. sonorensis, there are a multitude of Culicoides systems that can benefit from these next-generation control techniques. Each of these systems will have its own challenges and hurdles to consider before implementation; however, the ability to preemptively apply the knowledge gained from researching $C$. sonorensis will be invaluable to adapting these tools for use against other biting midge species.

\begin{abstract}
Abbreviations
AHSV: African horse sickness virus; BT: Bluetongue; BTV: Bluetongue virus; Cl: Cytoplasmic incompatibility; CRISPR: Clustered regularly interspaced short palindromic repeats; DENV: Dengue virus; EHD: Epizootic hemorrhagic disease; EHDV: Epizootic hemorrhagic disease virus; GM: Genetically modified; GMO: Genetically modified organism; HD: Hemorrhagic disease; IIT: Incompatible insect technique; RIDL: Release of insects carrying a dominant lethal; SIT: Sterile insect technique.
\end{abstract}

\section{Acknowledgements}

We would like to thank Alyssa Krafsur for helping to acquire images of $D$. melanogaster, C. sonorensis, and Ae. albopictus eggs. We would also like to thank the editor and two anonymous reviewers for their helpful comments and suggestions concerning the manuscript.

\section{Authors' contributions}

Conceptualization, $\mathrm{PS}$ and $\mathrm{CB}$; writing —original draft preparation, $\mathrm{PS}, \mathrm{CB}$, LC, ZA; writing-review and editing, PS, CB, LC, ZA; visualization, CB, PS. All authors read and approved the final manuscript.

\section{Funding}

Funding for this work was provided by Texas A\&M University Urban Entomology Endowment Fund, Texas Tech University startup funds, and the USDA.

\section{Availability of data and materials}

All data generated or analyzed during this study are included in this published article.

\section{Ethics approval and consent to participate}

Not applicable

\section{Consent for publication}

Not applicable

\section{Competing interests}

The authors declare that they have no competing interests

\section{Author details}

${ }^{1}$ Texas A\&M University, 370 Olsen Blvd, College Station, TX 77843, USA. ${ }^{2}$ Texas Tech University, 2901 Main St, Lubbock, TX 79409, USA. ${ }^{3}$ USDA-ARS Arthropod Borne Animal Disease Research Unit, 1515 College Ave, Manhattan, KS 66502, USA.

Received: 7 August 2020 Accepted: 5 December 2020

Published online: 07 January 2021

\section{References}

1. Borkent A. The biting midges, the Ceratopogonidae (Diptera). In: Marquardt C, editor. Biology of disease vectors. 2nd ed. San Diego: Elsevier Academic Press; 2005. p. 113-26.

2. Mellor P, Boorman J, Baylis M. Culicoides biting midges: their role as arbovirus vectors. Annu Rev Entomol. 2000;45(1):307-40.

3. Carpenter S, Groschup MH, Garros C, Felippe-Bauer ML, Purse BV. Culicoides biting midges, arboviruses and public health in Europe. Antiviral Res. 2013;100(1):102-13. https://doi.org/10.1016/j.antiviral.2013.07.020.
4. Sick F, Beer M, Kampen H, Wernike K. Culicoides biting midges-underestimated vectors for arboviruses of public health and veterinary importance. Viruses. 2019;11(4):376.

5. De Clercq K, Mertens P, De Leeuw I, Oura C, Houdart P, Potgieter AC, et al. Emergence of bluetongue serotypes in Europe, part 2: the occurrence of a BTV-11 strain in Belgium. Transbound Emerg Dis. 2009;56(910):355-61. https://doi.org/10.1111/j.1865-1682.2009.01092.x.

6. Vandenbussche F, De Leeuw I, Vandemeulebroucke E, De Clercq K. Emergence of bluetongue serotypes in Europe, part 1: description and validation of four real-time RT-PCR assays for the serotyping of bluetongue viruses BTV-1, BTV-6, BTV-8 and BTV-11. Transbound Emerg Dis. 2009;56(9-10):346-54. https://doi.org/10.1111/j.1865-1682.2009.01093 $x$.

7. Velthuis AG, Saatkamp HW, Mourits MC, de Koeijer AA, Elbers AR. Financial consequences of the Dutch bluetongue serotype 8 epidemics of 2006 and 2007. Prev Vet Med. 2010;93(4):294-304. https://doi. org/10.1016/j.prevetmed.2009.11.007.

8. Carpenter S, Wilson A, Mellor PS. Culicoides and the emergence of bluetongue virus in northern Europe. Trends Microbiol. 2009;17(4):172-8.

9. Hasler B, Howe KS, Di Labio E, Schwermer H, Stark KD. Economic evaluation of the surveillance and intervention programme for bluetongue virus serotype 8 in Switzerland. Prev Vet Med. 2012;103(2-3):93-111. https://doi.org/10.1016/j.prevetmed.2011.09.013.

10. Pfannenstiel RS, Mullens BA, Ruder MG, Zurek L, Cohnstaedt LW, Nayduch D. Management of North American Culicoides biting midges: current knowledge and research needs. Vector Borne Zoonotic Dis. 2015;15(6):374-84. https://doi.org/10.1089/vbz.2014.1705.

11. Benelli G, Buttazzoni L, Canale A, D'Andrea A, Del Serrone P, Delrio G, et al. Bluetongue outbreaks: looking for effective control strategies against Culicoides vectors. Res Vet Sci. 2017;115:263-70. https://doi. org/10.1016/j.rvsc.2017.05.023.

12. Harrup LE, Miranda MA, Carpenter S. Advances in control techniques for Culicoides and future prospects. Vet Ital. 2016;52(3-4):247-64.

13. Mullens BA, McDermott EG, Gerry AC. Progress and knowledge gaps in Culicoides ecology and control. Vet Ital. 2015;51(4):313-23. https://doi. org/10.12834/Vetlt.560.2675.1.

14. Savini G, MacLachlan NJ, Sanchez-Vizcaino J-M, Zientara S. Vaccines against bluetongue in Europe. Comp Immunol Microbiol Infect Dis. 2008;31(2-3):101-20.

15. Velthuis AG, Mourits MC, Saatkamp HW, De Koeijer AA, Elbers AR. Financial evaluation of different vaccination strategies for controlling the bluetongue virus serotype 8 epidemic in The Netherlands in 2008. PLoS ONE. 2011;6(5):e19612.

16. Gould F, Schliekelman P. Population genetics of autocidal control and strain replacement. Annu Rev Entomol. 2004;49(1):193-217. https://doi. org/10.1146/annurev.ento.49.061802.123344.

17. Knipling E. Possibilities of insect control or eradication through the use of sexually sterile males. J Econ Entomol. 1955;48(4):459-62.

18. Hoffmann AA, Montgomery BL, Popovici J, Iturbe-Ormaetxe I, Johnson $\mathrm{PH}$, Muzzi F, et al. Successful establishment of Wolbachia in Aedes populations to suppress dengue transmission. Nature. 2011;476(7361):454-7. https://doi.org/10.1038/nature10356.

19. Buchman A, Gamez S, Li M, Antoshechkin I, Li HH, Wang HW, et al. Broad dengue neutralization in mosquitoes expressing an engineered antibody. PLoS Pathog. 2020;16(1):e1008103. https://doi.org/10.1371/ journal.ppat.1008103.

20. Franz AW, Sanchez-Vargas I, Adelman ZN, Blair CD, Beaty BJ, James AA, et al. Engineering RNA interference-based resistance to dengue virus type 2 in genetically modified Aedes aegypti. Proc Natl Acad Sci USA. 2006;103(11):4198-203. https://doi.org/10.1073/pnas.0600479103.

21. Yen PS, James A, Li JC, Chen CH, Failloux AB. Synthetic miRNAs induce dual arboviral-resistance phenotypes in the vector mosquito Aedes aegypti. Commun Biol. 2018;1:11. https://doi.org/10.1038/s4200 3-017-0011-5.

22. Nayduch D, Cohnstaedt LW, Saski C, Lawson D, Kersey P, Fife M, et al. Studying Culicoides vectors of BTV in the post-genomic era: Resources, bottlenecks to progress and future directions. Virus Res. 2014;182:43-9. https://doi.org/10.1016/j.virusres.2013.12.009.

23. Jones RH. Mass production methods in rearing Culicoides variipennis (Coquillett). Bull World Health Organ. 1964;31(4):571-2. 
24. Mullens BA, Velten RK. Rearing Culicoides variipennis sonorensis (Diptera: Ceratopogonidae) on agar and nematodes. J Med Entomol. 1994;31(1):175-7. https://doi.org/10.1093/jmedent/31.1.175.

25. Mills MK, Nayduch D, Michel K. Inducing RNA interference in the arbovirus vector Culicoides sonorensis. Insect Mol Biol. 2015;24(1):105-14.

26. Campbell C, Wilson W. Differentially expressed midgut transcripts in Culicoides sonorensis (Diptera: Ceratopogonidae) following Orbivirus (Reoviridae) oral feeding. Insect Mol Biol. 2002;11 (6):595-604.

27. Nayduch D, Lee MB, Saski CA. The reference transcriptome of the adult female biting midge (Culicoides sonorensis) and differential gene expression profiling during teneral, blood, and sucrose feeding conditions. PLoS ONE. 2014;9(5):e98123.

28. Morales-Hojas R, Hinsley M, Armean IM, Silk R, Harrup LE, GonzalezUriarte A, et al. The genome of the biting midge Culicoides sonorensis and gene expression analyses of vector competence for bluetongue virus. BMC Genomics. 2018;19(1):624. https://doi.org/10.1186/s1286 4-018-5014-1.

29. Itô Y, Yamamura K. Role of population and behavioural ecology in the sterile insect technique. In: Dyck VA, Hendrichs J, Robinson AS, editors. Sterile insect technique: principles and practice in area-wide integrated pest management. Dordrecht: Springer Netherlands; 2005. p. 177-208.

30. Parker AG. Mass-rearing for sterile insect release. In: Dyck VA, Hendrichs J, Robinson AS, editors. Sterile insect technique: principles and practice in area-wide integrated pest management. Dordrecht: Springer Netherlands; 2005. p. 209-32.

31. Hendrichs J, Robinson AS, Cayol JP, Enkerlin W. Medfly areawide sterile insect technique programmes for prevention, suppression or eradication: the importance of mating behavior studies. Florida Entomologist. 2002:85(1):1-13.

32. Skoda SR, Phillips PL, Welch JB. Screwworm (Diptera: Calliphoridae) in the United States: response to and elimination of the 2016-2017 outbreak in Florida. J Med Entomol. 2018;55(4):777-86. https://doi. org/10.1093/jme/tjy049.

33. Vreysen MJB, Saleh KM, Ali MY, Abdulla AM, Zhu Z-R, Juma KG, et al. Glossina austeni (Diptera: Glossinidae) eradicated on the island of Unguja, Zanzibar, using the sterile insect technique. J Econ Entomol. 2000;93(1):123-35. https://doi.org/10.1603/0022-0493-93.1.123.

34. Alphey L, Benedict M, Bellini R, Clark GG, Dame DA, Service MW et al. Sterile-insect methods for control of mosquito-borne diseases: an analysis. Vector Borne Zoonotic Dis. 2010; 10(3): 295-311. https://doi. org/10.1089/vbz.2009.0014.

35. Brelsfoard CL, Mains JW, Mulligan S, Cornel A, Holeman J, Kluh S, et al. Aedes aegypti males as vehicles for insecticide delivery. Insects. 2019;10(8):230. https://doi.org/10.3390/insects10080230.

36. Werren JH, Baldo L, Clark ME. Wolbachia: master manipulators of invertebrate biology. Nat Rev Microbiol. 2008;6(10):741.

37. Mee PT, Weeks AR, Walker PJ, Hoffmann AA, Duchemin J-B. Detection of low-level Cardinium and Wolbachia infections in Culicoides. Appl Environ Microbiol. 2015;81(18):6177-88.

38. Pagès N, Muñoz-Muñoz F, Verdún M, Pujol N, Talavera S. First detection of Wolbachia-infected Culicoides (Diptera: Ceratopogonidae) in Europe: Wolbachia and Cardinium infection across Culicoides communities revealed in Spain. Parasites Vectors. 2017;10(1):582. https://doi. org/10.1186/s13071-017-2486-9.

39. Covey H, Hall RH, Krafsur A, Matthews ML, Shults PT, Brelsfoard CL. Cryptic Wolbachia (Rickettsiales: Rickettsiaceae) Detection and prevalence in Culicoides (Diptera: Ceratopogonidae) midge populations in the United States. J Med Entomol. 2020;57(4):1262-9. https://doi.org/10.1093/jme/ tjaa003.

40. Moreira LA, Iturbe-Ormaetxe I, Jeffery JA, Lu G, Pyke AT, Hedges LM, et al. A Wolbachia symbiont in Aedes aegypti limits infection with dengue, chikungunya, and Plasmodium. Cell. 2009;139(7):1268-78. https:// doi.org/10.1016/j.cell.2009.11.042.

41. van den Hurk AF, Hall-Mendelin S, Pyke AT, Frentiu FD, McElroy K, Day A, et al. Impact of Wolbachia on infection with chikungunya and yellow fever viruses in the mosquito vector Aedes aegypti. PLoS Negl Trop Dis. 2012;6(11):e1892. https://doi.org/10.15698/mic2016.07.513.

42. Caragata EP, Dutra HL, Moreira LA. Inhibition of Zika virus by Wolbachia in Aedes aegypti. Microb Cell. 2016;3(7):293-5. https://doi.org/10.1371/ journal.pntd.0005496.
43. Tan $\mathrm{CH}$, Wong PJ, Li MI, Yang H, Ng LC, Neill SL. WMel limits zika and chikungunya virus infection in a Singapore Wolbachia-introgressed Ae. aegypti strain, wMel-Sg. PLoS Negl Trop Dis. 2017;11(5):e0005496.

44. Flores HA, O'Neill SL. Controlling vector-borne diseases by releasing modified mosquitoes. Nat Rev Microbiol. 2018;16(8):508-18. https://doi. org/10.1038/s41579-018-0025-0.

45. Bourtzis K, Dobson SL, Xi Z, Rasgon JL, Calvitti M, Moreira LA, et al. Harnessing mosquito-Wolbachia symbiosis for vector and disease control. Acta Trop. 2014;132(Suppl):S150-63. https://doi.org/10.1016/j.actat ropica.2013.11.004.

46. Werren JH, Zhang W, Guo LR. Evolution and phylogeny of Wolbachia: reproductive parasites of arthropods. Proc R Soc Lond B Biol Sci. 1995:261(1360):55-63.

47. Mains JW, Brelsfoard CL, Rose RI, Dobson SL. Female adult Aedes albopictus suppression by Wolbachia-infected male mosquitoes. Sci Rep. 2016;6:33846.

48. Mains JW, Kelly PH, Dobson KL, Petrie WD, Dobson SL. Localized control of Aedes aegypti (Diptera: Culicidae) in Miami, FL, via inundative releases of Wolbachia-infected male mosquitoes. J Med Entomol. 2019;56(5):1296-303. https://doi.org/10.1093/jme/tjz051.

49. O'Neill SL, Ryan PA, Turley AP, Wilson G, Retzki K, Iturbe-Ormaetxe I, et al. Scaled deployment of Wolbachia to protect the community from dengue and other Aedes transmitted arboviruses. Gates Open Res. 2018;2:36. https://doi.org/10.12688/gatesopenres.12844.3.

50. Adelman ZN, Basu S, Myles KM. Engineering pathogen resistance in mosquitoes. In: Adelman ZN, editor. Genetic control of malaria and dengue. Amsterdam: Elsevier; 2016. p. 277-304.

51. Ghosh A, Jasperson D, Cohnstaedt LW, Brelsfoard CL. Transfection of Culicoides sonorensis biting midge cell lines with Wolbachia pipientis. Parasites Vectors. 2019;12(1):483. https://doi.org/10.1186/s1307 1-019-3716-0.

52. Committee on Gene Drive Research in Non-Human Organisms: Recommendations for Responsible Conduct; Board on Life Sciences; Division on Earth and Life Studies; National Academies of Sciences, Engineering, and Medicine. Gene drives on the horizon: advancing science, navigating uncertainty, and aligning research with public values. Washington DC: National Academies Press; 2016.

53. Adelman ZN, Anderson MA, Morazzani EM, Myles KM. A transgenic sensor strain for monitoring the RNAi pathway in the yellow fever mosquito Aedes aegypti. Insect Biochem Mol Biol. 2008;38(7):705-13.

54. Reid W, O'Brochta DA. Applications of genome editing in insects. Curr Opin Insect Sci. 2016;13:43-54. https://doi.org/10.1016/j. cois.2015.11.001.

55. Alphey L, McKemey A, Nimmo D, Neira Oviedo M, Lacroix R, Matzen K, et al. Genetic control of Aedes mosquitoes. Pathog Glob Health. 2013;107(4):170-9. https://doi.org/10.1179/2047773213Y.0000000095.

56. Black WC, Alphey L, James AA. Why RIDL is not SIT. Trends Parasitol. 2011;27(8):362-70. https://doi.org/10.1016/j.pt.2011.04.004.

57. Gong P, Epton MJ, Fu G, Scaife S, Hiscox A, Condon KC, et al. A dominant lethal genetic system for autocidal control of the Mediterranean fruitfly. Nat Biotechnol. 2005;23(4):453-6. https://doi.org/10.1038/nbt1071.

58. Ran FA, Hsu PD, Wright J, Agarwala V, Scott DA, Zhang FJN. Genome engineering using the CRISPR-Cas9 system. Nat Protoc. 2013:8(11):2281.

59. Handler AM. Use of the piggyBac transposon for germ-line transformation of insects. Insect Biochem Mol Biol. 2002;32(10):1211-20. https:// doi.org/10.1016/s0965-1748(02)00084-X.

60. Galizi R, Hammond A, Kyrou K, Taxiarchi C, Bernardini F, O'Loughlin SM, et al. A CRISPR-Cas9 sex-ratio distortion system for genetic control. Nature. 2016;6:31139.

61. Kyrou K, Hammond AM, Galizi R, Kranjc N, Burt A, Beaghton AK, et al. A CRISPR-Cas9 gene drive targeting doublesex causes complete population suppression in caged Anopheles gambiae mosquitoes. Nature. 2018;36(11):1062.

62. Gossen $\mathrm{M}$, Bujard $\mathrm{H}$. Tight control of gene expression in mammalian cells by tetracycline-responsive promoters. Proc Natl Acad Sci USA. 1992;89(12):5547-51.

63. Burt A, Crisanti A. Gene drive: evolved and synthetic. ACS Chem Biol. 2018;13(2):343-6. https://doi.org/10.1021/acschembio.7b01031.

64. Chen $\mathrm{CH}$, Huang H, Ward CM, Su JT, Schaeffer LV, Guo M, et al. A synthetic maternal-effect selfish genetic element drives population replacement in Drosophila. Science. 2007;316(5824):597-600. 
65. Gantz VM, Bier E. The mutagenic chain reaction: A method for converting heterozygous to homozygous mutations. Science. 2015;348(6233):442. https://doi.org/10.1126/science.aaa5945.

66. Gantz VM, Jasinskiene N, Tatarenkova O, Fazekas A, Macias VM, Bier E, et al. Highly efficient Cas9-mediated gene drive for population modification of the malaria vector mosquito Anopheles stephensi. Proc Natl Acad Sci USA. 2015;112(49):E6736-43.

67. Kyrou K, Hammond AM, Galizi R, Kranjc N, Burt A, Beaghton AK, et al. A CRISPR-Cas9 gene drive targeting doublesex causes complete population suppression in caged Anopheles gambiae mosquitoes. Nat Biotechnol. 2018;36(11):1062-6.

68. Li M, Yang T, Kandul NP, Bui M, Gamez S, Raban R, et al. Development of a confinable gene drive system in the human disease vector Aedes aegypti. Elife. 2020. https://doi.org/10.7554/eLife.51701.

69. Simoni A, Hammond AM, Beaghton AK, Galizi R, Taxiarchi C, Kyrou K, et al. A male-biased sex-distorter gene drive for the human malaria vector Anopheles gambiae. Nat Biotechnol. 2020. https://doi.org/10.1038/ s41587-020-0508-1.

70. Marshall JM, Akbari OS. Gene drive strategies for population replacement. In: Adelman ZN, editor. Genetic control of malaria and dengue. Amsterdam: Elsevier; 2016. p. 169-200.

71. Marshall JM, Raban RR, Kandul NP, Edula JR, León TM, Akbari OS. Winning the Tug-of-War between effector gene design and pathogen evolution in vector population replacement strategies. Front Genet. 2019;10:1072. https://doi.org/10.3389/fgene.2019.01072.

72. Alphey L. Genetic control of mosquitoes. Annu Rev Entomol. 2014;59:205-24

73. Gerry AC, Mullens BA. Response of Male Culicoides variipennis sonorensis (Diptera: Ceratopogonidae) to carbon dioxide and observations of mating behavior on and near cattle. J Med Entomol. 1998;35(3):239-44. https://doi.org/10.1093/jmedent/35.3.239.

74. Morris AC, Eggleston P, Crampton JM. Genetic transformation of the mosquito Aedes aegypti by micro-injection of DNA. Med Vet Entomol. 1989;3(1):1-7.

75. Martin-Martin I, Aryan A, Meneses C, Adelman ZN, Calvo E. Optimization of sand fly embryo microinjection for gene editing by CRISPR/Cas9. PLoS Negl Trop Dis. 2018;12(9):e0006769. https://doi.org/10.1371/journ al.pntd.0006769.

76. Basu S, Aryan A, Overcash JM, Samuel GH, Anderson MAE, Dahlem TJ, et al. Silencing of end-joining repair for efficient site-specific gene insertion after TALEN/CRISPR mutagenesis in Aedes aegypti. Proc Natl Acad Sci USA. 2015;112(13):4038. https://doi.org/10.1073/pnas.1502370112.

77. Kistler Kathryn E, Vosshall Leslie B, Matthews BJ. Genome Engineering with CRISPR-Cas9 in the Mosquito Aedes aegypti. Cell Rep. 2015;11(1):51-60. https://doi.org/10.1016/j.celrep.2015.03.009.

78. Amenya DA, Bonizzoni M, Isaacs AT, Jasinskiene N, Chen H, Marinotti $\mathrm{O}$, et al. Comparative fitness assessment of Anopheles stephensi transgenic lines receptive to site-specific integration. Insect Mol Biol. 2010;19(2):263-9. https://doi.org/10.1111/j.1365-2583.2009.00986.x.

79. Volohonsky G, Terenzi O, Soichot J, Naujoks DA, Nolan T, Windbichler $\mathrm{N}$, et al. Tools for Anopheles gambiae Transgenesis. G3 (Bethesda). 2015;5(6):1151-63. https://doi.org/10.1534/g3.115.016808.

80. Nolan T, Bower TM, Brown AE, Crisanti A, Catteruccia F. piggyBacmediated germline transformation of the malaria mosquito Anopheles stephensi using the red fluorescent protein dsRED as a selectable marker. J Biol Chem. 2002;277(11):8759-62.

81. Jones R, Foster N. Oral infection of Culicoides variipennis with bluetongue virus: development of susceptible and resistant lines from a colony population. J Med Entomol. 1974;11(3):316-23.

82. Bell-Sakyi L, Mohd Jaafar F, Monsion B, Luu L, Denison E, Carpenter S, et al. Continuous cell lines from the European biting midge Culicoides nubeculosus (Meigen, 1830). Microorganisms. 2020;8(6):825.

83. Erram D, Burkett-Cadena N. Laboratory rearing of Culicoides stellifer (Diptera: (eratopogonidae), a suspected vector of orbiviruses in the United States. J Med Entomol. 2019;57(1):25-32. https://doi.org/10.1093/jme/ tjz154.

84. Bellis GA. Studies on the taxonomy of Australasian species of Culicoides latreille (Diptera: Ceratopogonidae). St Lucia: The University of Queensland; 2013.

85. Boorman J. Rearing Culicoides obsoletus (Diptera, Ceratopogonidae) on agar cultures of nematodes. Prog Clin Biol Res. 1985;178:229.
86. Sohier C, Matthijs S, De Regge N. Comparing different larval food sources and temperature regimes for the rearing of Culicoides obsoletus/scoticus complex midges, the predominant bluetongue, and Schmallenberg virus vectors in Northern Europe. Multidisciplinary Digital Publish Instit Proc. 2020;50(1):80.

87. Veronesi E, Venter G, Labuschagne K, Mellor P, Carpenter S. Life-history parameters of Culicoides (Avaritia) imicola Kieffer in the laboratory at different rearing temperatures. Vet Parasitol. 2009;163(4):370-3.

88. Shults P, Borkent A, Gold R. The pupa of Culicoides sonorensis Wirth and Jones (Diptera: Ceratopogonidae) — first detailed description of this stage of the bluetongue virus vector. Ann Entomol Soc Am. 2016;109(2):280-318. https://doi.org/10.1093/aesa/sav119.

89. Wirth WW, Jones RH. The North American Subspecies of Culicoides variipennis (Diptera, Heleidae). US Dep Agric Tech Bull. 1957;1170:1-35.

90. Genoud AP, Basistyy R, Williams GM, Thomas BP. Optical remote sensing for monitoring flying mosquitoes, gender identification and discussion on species identification. Appl Phys B. 2018;124(3):46.

91. Papathanos PA, Bossin HC, Benedict MQ, Catteruccia F, Malcolm CA, Alphey L, et al. Sex separation strategies: past experience and new approaches. Malar J. 2009;8(2):S5.

92. Lowe R, Fowler J, Bailey D, Dame D, Savage K. Separation of sexes of adult Anopheles albimanus by feeding of insecticide-laden blood. Mosq News. 1981;41(4):634-8.

93. Crawford JE, Clarke DW, Criswell V, Desnoyer M, Cornel D, Deegan B, et al. Efficient production of male Wolbachia-infected Aedes aegypti mosquitoes enables large-scale suppression of wild populations. Nat Biotechnol. 2020;38(4):482-92. https://doi.org/10.1038/s4158 7-020-0471-x

94. Condon KC, Condon GC, Dafa'alla TH, Fu G, Phillips CE, Jin L, et al. Genetic sexing through the use of Y-linked transgenes. Insect Biochem Mol Biol. 2007:37(11):1168-76.

95. Lutrat C, Giesbrecht D, Marois E, Whyard S, Baldet T, Bouyer J. Sex sorting for pest control: It's raining men! Trends Parasitol. 2019;35(8):649-62. https:// doi.org/10.1016/j.pt.2019.06.001.

96. Heinrich JC, Scott MJ. A repressible female-specific lethal genetic system for making transgenic insect strains suitable for a sterile-release program. Proc Natl Acad Sci USA. 2000;97(15):8229-32.

97. Atkinson MP, Su Z, Alphey N, Alphey LS, Coleman PG, Wein LM. Analyzing the control of mosquito-borne diseases by a dominant lethal genetic system. Proc Natl Acad Sci USA. 2007;104(22):9540-5.

98. McDonald IC. A male-producing strain of the house fly. Science. 1971;172(3982):489.

99. Damiens D, Marquereau L, Lebon C, Le Goff G, Gaudillat B, Habchi-Hanriot $\mathrm{N}$, et al. Aedes albopictus adult medium mass rearing for SIT program development. Insects. 2019;10(8):246. https://doi.org/10.3390/insects100 80246.

100. Bukauskaite D, lezhova TA, Ilgunas M, Valkiunas G. High susceptibility of the laboratory-reared biting midges Culicoides nubeculosus to Haemoproteus infections, with review on Culicoides species that transmit avian haemoproteids. Parasitology. 2019;146(3):333-41. https://doi.org/10.1017/S0031 182018001373.

101. Du W, Hu C, Yu C, Tong J, Qiu J, Zhang S, et al. Comparison between pupal and adult $X$-ray radiation, designed for the sterile insect technique for Aedes albopictus control. Acta Trop. 2019;199:105110. https://doi. org/10.1016/j.actatropica.2019.105110.

102. Zheng X, Zhang D, Li Y, Yang C, Wu Y, Liang X, et al. Incompatible and sterile insect techniques combined eliminate mosquitoes. Nature. 2019;572(7767):56-61. https://doi.org/10.1038/s41586-019-1407-9.

103. Ritchie SA, van den Hurk AF, Smout MJ, Staunton KM, Hoffmann AA. Mission accomplished? We need a guide to the "post release" world of Wolbachia for Aedes-borne disease control. Trends Parasitol. 2018;34(3):217-26. https ://doi.org/10.1016/j.pt.2017.11.011.

104. Carvalho DO, McKemey AR, Garziera L, Lacroix R, Donnelly CA, Alphey $L$, et al. Suppression of a field population of Aedes aegypti in Brazil by sustained release of transgenic male mosquitoes. PLoS Negl Trop Dis. 2015;9(7):e0003864. https://doi.org/10.1371/journal.pntd.0003864.

105. Gorman K, Young J, Pineda L, Márquez R, Sosa N, Bernal D, et al. Short-term suppression of Aedes aegypti using genetic control does not facilitate Aedes albopictus. Pest Manag Sci. 2016;72(3):618-28.

106. Harris AF, McKemey AR, Nimmo D, Curtis Z, Black I, Morgan SA, et al. Successful suppression of a field mosquito population by sustained release of 
engineered male mosquitoes. Nat Biotechnol. 2012;30(9):828-30. https:// doi.org/10.1038/nbt.2350.

107. Environmental Protection Agency (EPA). Issuance of an experimental use permit. Fed Reg. 2020;85(111):35307.

108. Kluiters G, Swales H, Baylis M. Local dispersal of palaearctic Culicoides biting midges estimated by mark-release-recapture. Parasites Vectors. 2015;8(1):86.

109. Sanders CJ, Harrup LE, Tugwell LA, Brugman VA, England M, Carpenter S. Quantification of within-and between-farm dispersal of Culicoides biting midges using an immunomarking technique. J Appl Ecol. 2017;54(5):1429-39.

110. Zimmerman R, Barker S, Turner EC Jr. Swarming and mating behavior of a natural population of Culicoides variipennis (Diptera: Ceratopogonidae). J Med Entomol. 1982:19(2):151-6.

111. Downes J. Observations on the swarming flight and mating of Culicoides (Diptera: Ceratopogonidae). Ecol Entomol. 1955;106(Pt. 5):213-36.

112. Borkent A. The pupae of the biting midges of the world (Diptera: Ceratopogonidae), with a generic key and analysis of the phylogenetic relationships between genera. Zootaxa. 2014;3879(1):1-327.

113. Jacquet S, Huber K, Pages N, Talavera S, Burgin LE, Carpenter S, et al. Range expansion of the Bluetongue vector, Culicoides imicola, in continental France likely due to rare wind-transport events. Sci Rep. 2016. https://doi. org/10.1038/srep27247.

114. Blackwell A, Page SJ. Biting midges and tourism in Scotland. In: Wilks J, Stephen J, Moore F, editors. Managing tourist health and safety in the new millennium. Abingdon: Routledge Press; 2003. p. 177-96.

115. Fox I, Garcia-Moll I. The Culicoides of the international airport, Isla Verde, Puerto Rico, as shown by light traps. Mosq News. 1961;21 (2):120-32.

116. Wirth W, Arnaud P. Polynesian biting midges of the genus Culicoides (Diptera: Ceratopogonidae). Pacific insects. 1969;11:507-20.

117. McGregor BL, Sloyer KE, Sayler KA, Goodfriend O, Krauer JMC, Acevedo C, et al. Field data implicating Culicoides stellifer and Culicoides venustus (Diptera: Ceratopogonidae) as vectors of epizootic hemorrhagic disease virus. Parasites Vectors. 2019;12(1):258. https://doi.org/10.1186/s1307 1-019-3514-8.

118. Kim Y-H, Oem J-K, Lee E-Y, Lee K-K, Kim S-H, Lee M-H, et al. Seroprevalence of five arboviruses in sentinel cattle as part of nationwide surveillance in South Korea, 2009-2012. J Vet Med Sci. 2015;77(2):247-50.

119. Mayo CE, Mullens BA, Gerry AC, Barker CM, Mertens PP, Maan S, et al. The combination of abundance and infection rates of Culicoides sonorensis estimates risk of subsequent bluetongue virus infection of sentinel cattle on California dairy farms. Vet Parasitol. 2012:187(1-2):295-301.

120. Jacquet S, Garros C, Lombaert E, Walton C, Restrepo J, Allene X, et al. Colonization of the Mediterranean basin by the vector biting midge species Culicoides imicola: an old story. Mol Ecol. 2015;24(22):5707-25. https://doi. org/10.1111/mec.13422.

121. Onyango MG, Aitken NC, JackC, Chuah A, Oguya J, Djikeng A, et al. Genotyping of whole genome amplified reduced representation libraries reveals a cryptic population of Culicoides brevitarsis in the Northern Territory, Australia. BMC Genomics. 2016;17(1):769. https://doi.org/10.1186/s1286 4-016-3124-1.
122. Pili E, Carcangiu L, Oppo M, Marchi A. Genetic structure and population dynamics of the biting midges Culicoides obsoletus and Culicoides scoticus: implications for the transmission and maintenance of bluetongue. Med Vet Entomol. 2010;24(4):441-8. https://doi.org/10.111 1/j.1365-2915.2010.00887.

123. Gibbs E, Greiner E. Serological observations on the epidemiology of bluetongue virus infections in the Caribbean and Florida. Prog Clin Biol Res. 1985;178:563-70.

124. Spickler AR, Roth JA. Emerging and exotic diseases of animals. lowa State: Institute for International Cooperation in Animal Biologics; 2006.

125. TabachnickW. Culicoides variipennis and bluetongue virus epidemiology in the United States. Annu Rev Entomol. 1996;41:23-43.

126. Rushton J, Lyons N. Economic impact of bluetongue: a review of the effects on production. Vet Ital. 2015;51(4):401-6.

127. Roughton RD. An outbreak of a hemorrhagic disease in white-tailed deer in Kentucky. J Wild Dis. 1975;11(2):177-86.

128. Ruder MG, Johnson D, Ostlund E, Allison AB, Kienzle C, Phillips JE, et al. The first 10 years (2006-15) of epizootic hemorrhagic disease virus serotype 6 in the USA. JWildl Dis. 2017;53(4):901-5.

129. Saegerman C, Bolkaerts B, Baricalla C, Raes M, Wiggers L, de Leeuw I, et al. The impact of naturally-occurring, trans-placental bluetongue virus serotype-8 infection on reproductive performance in sheep. Vet J. 2011;187(1):72-80. https://doi.org/10.1016/j.tvjl.2009.11.012.

130. Velten RK, Mullens BA. Field morphological variation and laboratory hybridization of Culicoides variipennis sonorensis and C. v.occidentalis (Diptera:Ceratopogonidae) in southern California. J Med Entomol. 1997;34(3):277-84

131. Holbrook FR, TabachnickWJ, Brady R. Genetic variation in populations of Culicoides variipennis complex in the six New England states, USA. Med Vet Entomol. 1996;10(2):173-80. https://doi.org/10.1111/j.1365-2915.1996. tb00725.x.

132. Holbrook FR, TabachnickWJ, Schmidtmann ET, McKinnon CN, Bobian RJ, Grogan WL. Sympatry in the Culicoides variipennis Complex (Diptera: Ceratopogonidae): a taxonomic reassessment. J Med Entomol. 2000;37(1):6576. https://doi.org/10.1603/0022-2585-37.1.65.

133. Beer M, Conraths FJ, Van Der Poel WHM. 'Schmallenberg virus'-a novel orthobunyavirus emerging in Europe. Epidemiol Infect. 2013;141(1):1-8. https://doi.org/10.1017/S0950268812002245.

134. King S, Rajko-Nenow P, Ashby M, Frost L, Carpenter S, Batten C. Outbreak of African horse sickness in Thailand. Transboundary Emerg Dis. 2020. https ://doi.org/10.1111/tbed.13701.

135. MacLachlan NJ, Guthrie AJ. Re-emergence of bluetongue, African horse sickness, and other Orbivirus diseases. Vet Res. 2010;41(6):35. https://doi. org/10.1051/vetres/2010007.

\section{Publisher's Note}

Springer Nature remains neutral with regard to jurisdictional claims in published maps and institutional affiliations. 